\title{
Figurações da cidade: um olhar para a literatura como fonte da história urbana ${ }^{1}$
}

\section{Ana Claudia Veiga de Castro $^{2}$}

RESUMO: Nota-se nas últimas décadas um interesse renovado pelas possíveis conexões entre a história e a literatura. Contudo, os rendimentos dessa ligação continuam sendo em grande medida um desafio. Do ponto de vista de uma história urbana, a incorporação de gêneros literários e discursos não especializados ao acervo de fontes tradicionais, além de ampliar o catálogo documental mobilizado, também tem contribuído para a consolidação de um subcampo, a história cultural urbana, cuja perspectiva analítica modifica os modos de compreensão do artefato urbano. Este artigo propõe uma reflexão sobre as potencialidades do uso da literatura como fonte para a história urbana, e a faz a partir de três entradas. Inicialmente, apresenta um comentário sobre duas obras hoje clássicas que tangenciam o tema. Em seguida, busca recuperar algumas referências dentro do campo da história da cidade no Brasil. Por último, reflete sobre três incursões da autora na temática em questão, com o intuito de apresentar algumas conclusões parciais que apontem um caminho de trabalho.

PALAVRAS-CHAVE: História urbana. Literatura. Cidade. Historiografia.

ABSTRACT: In the last decades it is noted a renewed interest on the possible connections between History and Literature. However, the outcome of these connections remains largely a challenge. From the point of view of Urban History, the incorporation of literary genres and discourses not specialized to traditional sources collection, in addition to expanding the mobilized documentary catalog, has also contributed to the consolidation of a subfield, Urban Cultural History, whose analytical perspective expands the ways of understanding the urban artifact. This article proposes a reflection on the potential of the use of Literature as a source for Urban History, from three inputs. Initially, it presents a review of two works today classic that touches the theme. Then, it seeks to recover some references within the field of history of the city in Brazil. Finally, it reflects on three author's works on the subject involved, in order to present some partial conclusions that can point a working path.
1. Versões parciais deste artigo foram apresentadas no III Encontro Nacional de Pesquisadores em Arquitetura e Urbanismo - Enanparq (São Paulo, 2014) e no XXVIII Simpósio Nacional de História da Associação Nacional de História - Anpuh (Florianópolis, 2015). Agradeço a Paulo Garcez, Denilson Botelho, Adriano Duarte e Joana Mello, cujos comentários nas duas mesas auxiliaram no desenvolvimento das questões aqui tratadas.

2. Docente da Faculdade de Arquitetura e Urbanismo (FAU) / Universidade de São Paulo (USP). E-mail: $<$ anacvcastro@usp.br>.

KEYWORDS: Urban History. Literature. City. Historiography. 
Littérature et histoire ne sont pas, nous le savons, deux champs étanches, il s'agit bien plutôt d'un vieux couple avec une longue chronique de querelles.

François Hartog, Ce que la littérature fait de l'histoire et à I'histoire, 2008.

Já se disse uma vez que "sempre existiu uma íntima ligação entre a literatura e as cidades", pois é nas cidades que se encontram "as instituições literárias básicas: editoras, patronos, bibliotecas, museus, livrarias, teatros, revistas". É também no espaço urbano que "as pressões, as novidades, os debates, o lazer, o dinheiro, a alta rotatividade das pessoas, os fluxos dos visitantes, o som de muitas línguas, a rápida troca de ideias e estilos, a oportunidade de especialização artística" se realizam. Contudo, essa ligação se afirmou não apenas pelo fato de a cidade ser o local fundamental da circulação literária, mas também e mais importante, porque o artista moderno teria sido "capturado pelo espírito da cidade moderna" (BRADBURY, 1989, p. 77). Não à toa, o século XIX vê surgir um gênero literário novo, o romance, dando conta de práticas urbanas informadas pela Revolução Industrial e pelos seus efeitos.

O romance, como defendeu o crítico italiano Franco Moretti, "essa primeira forma simbólica verdadeiramente mundial", desafiou e desestabilizou as convenções ao oferecer relatos da vida cotidiana, histórias sobre os recônditos da alma humana, percursos de formação. Ao tematizar os embates entre indivíduo e sociedade, aproximou seus leitores da vida social em sua multiplicidade, dialogando com as distintas esferas da existência e fazendo dessa literatura um sistema planetário (MORETTI, 2009, p. 11). Além disso, ao inventar do mundo seu objeto, o romance fez do caráter temporal e histórico da ação dos homens a sua questão central e fundamental. Numa sociedade cada vez mais fraturada, a própria narrativa assumiria essa forma, fraturando-se pela perda da onisciência do narrador, a quebra do encadeamento causal, a interiorização dos conflitos e a multiplicação das vozes narrativas. A sociedade moderna traduzia-se na própria forma-romance: "O romance é o mundo moderno" (MAGRIS, 2009, p. 1.016). Dito de outro modo, esse gênero literário se tornava indissociável daquela nova experiência urbana.

Ao mesmo tempo, não apenas em romances, mas também na poesia ou nas crônicas cotidianas, a própria cidade passava a ser uma personagem, deixando de ser apenas palco ou cenário dos acontecimentos. Basta pensarmos na Paris de Baudelaire ou de Zola, na Londres de Dickens, na Petersburgo de Dostoievski, na São Paulo de Mário de Andrade ou Alcântara Machado, na Buenos Aires de Borges ou Roberto Arlt. Autores, entre tantos outros, que expressaram a sensibilidade moderna vinculada ao ambiente urbano, formulando imagens e oferecendo experiências formais que permitem ainda hoje nos aproximarmos daquelas cidades. 
Mas a despeito de haver um interesse renovado pelas conexões possíveis entre literatura e história nas últimas décadas - como demostraram os organizadores de um número recente da revista dos Annales dedicado a discutir essa relação (ANHEIN; LILTI, 2010) ${ }^{3}$, não se pode desprezar, como também se indicou ali, que a tradicional divisão entre o trabalho de historiadores e sociólogos que estudam a recepção e utilizações de obras, e o literário, destinado a sua gênese e interpretação, jamais se enfraqueceu (ANHEIN; LILTI, 2010). ${ }^{4}$ Por isso, os rendimentos dessa ligação continuam sendo em grande medida um desafio para os pesquisadores que querem enfrentar tal questão.

$\bigcirc$ que se propõe aqui é justamente esboçar algumas considerações sobre o tema, no que diz respeito especificamente à história urbana, ou o que vem sendo chamado de história cultural urbana. ${ }^{5}$ Tradicionalmente, as fontes utilizadas pela história urbana se restringiam a uma literatura técnica e legal. Mas, ao menos desde a década de 1980, os gêneros literários e os discursos não especializados - ensaio, narrativa, poesia, dramaturgia, crônica de viagens, representação pictórica e cinematográfica, entre outros - foram gradativamente incorporados ao catálogo das fontes documentais da história urbana, levando ao surgimento de um novo subcampo disciplinar: a história cultural urbana (ALMANDOZ, 2002). ${ }^{\circ}$ A discussão sobre a formação desse novo campo ou subcampo, entretanto, não é algo realmente assentado, levando pesquisadores a refletir sobre o que teria levado a cultura a ocupar um espaço tão destacado no fazer histórico sobre as cidades.

Para o arquiteto e historiador argentino Adrián Gorelik, por exemplo, não se trataria de uma nova disciplina - a história cultural urbana -, mas de uma nova perspectiva de análise que, ao cruzar diversos campos do conhecimento, buscaria produzir uma leitura mais complexa para um artefato por natureza complexo. Nas suas palavras: "tentar pensar a história cultural urbana como uma disciplina seria supor prolegômenos de leitura e corpus teóricos específicos, e me parece que isso é absolutamente impossível e até mesmo indesejável" (GORELIK, 2009, p. 249). Sendo a cidade esse objeto aberto e multifacetado, ela recusaria qualquer intenção de "redução teórica", o que, longe de ser uma "falha" ou "desvio", pode ao contrário ser tomado como uma vantagem metodológica. Desse modo,

A história cultural urbana abre-se a todas as disciplinas que tenham algo a dizer sobre a cidade, e com isso redefine todas as questões que giram em torno dela: a literatura, a política, a sociologia, a arquitetura, que também acabam reformuladas ao passarem pelo filtro da cidade. (GORELIK, 2009, p. 249)

Segundo a historiadora da arquitetura norte-americana Nancy Stieber, essa tendência ao "cultural" vislumbrada nos escritos de história não apenas urbana, mas também da arquitetura, esteve ligada ao abandono das grandes narrativas e dos esquemas estruturalistas que pautaram a história até os anos 1960, em busca de construções mais pormenorizadas que pudessem dar ênfase a uma espécie de autonomia das formas culturais, rejeitando-se a abstração em favor de se mapear
3. O sucesso do Grupo de Trabalho (GT) História, Literatura e Sociedade da Anpuh, que em seu segundo ano de funcionamento foi um dos simpósios temáticos que mais recebeu propostas de participação - segundo informaram seus coordenadores Denilson Botelho (Universidade Federal de São Paulo - Unifesp) e Adriano Duarte (Universidade Federal de Santa Catarina - UFSC) -, atesta esse interesse também no Brasil.

4. Para uma visão sobre o nascimento da sociologia, sua pretensão "científica" e as disputas com a literatura como o âmbito dos estudos da sociedade, ver Wolf Lepenies (1996).

5. Não se pode desprezar a contribuição de Chartier para uma história centrada num questionamento histórico da literatura. Entre outros do mesmo autor, ver Roger Chartier (2012). Mas ainda que seus trabalhos tragam elementos para o entendimento do mundo urbano, certamente seu ponto é outro.

6. Ver ainda Ronal Raminelli (1997). 
7. Deixa-se de lado outra importante vertente da literatura de ficção, a dramaturgia, que vem recebendo tratamento especial no campo das ciências humanas. Ver, entre outros, Christophe Charle (2012); Maria Arminda do Nascimento Arruda (2001), em capítulo dedicado a Jorge de Lima; Heloísa Pontes (2011), autores que exploraram as possíveis relações entre dramaturgia e cidade, não necessariamente dentro do campo da história das cidades. Ainda nesse sentido, não se pode esquecer do ensaio La cour et la ville, de Auerbach, que, explorando cruzamentos entre teatro e cidade, oferece uma vertente analítica que também pode trazer subsídios para a discussão (AUERBACH, 2007). Porém, neste artigo, ao se privilegiar a literatura da leitura individual - feita em silêncio e individualmente -, a dramaturgia e seus usos não serão aqui abordados.

8. Para um aprofundamento na discussão, ver Terry Eagleton, sobretudo a introdução "O que literatura?" (2006, p. 1-24). "práticas materiais, expondo a tomada da cultura como agente ativo ao invés de reflexão passiva" (STIEBER, 1999).

Isso se conjugaria com a intenção de ler a literatura como um índice de produção da cidade, perspectiva que informa tais estudos culturais no campo, agora sim, da história urbana. Ora, se é evidente que a ampliação de fontes e os cruzamentos disciplinares enriquecem a leitura histórica que se faz das cidades, resta pensar como isso se dá efetivamente. Sistematizando algumas formulações sobre o tema, podemos começar a discutir as potencialidades e os limites que a literatura como fonte para o estudo da história urbana coloca, precisando melhor a sua incorporação nesse acervo ampliado de documentos.

Inicio lembrando de dois trabalhos que são sempre citados quando se trata de pensar as relações entre cidade, literatura e história. A seguir, busco fazer um breve apanhado do tema no Brasil, indicando os caminhos trilhados pela historiografia local. Para finalizar, recupero algumas incursões no tema a partir de trabalhos anteriores e apresento aspectos de uma pesquisa em andamento. Ao assentar questões dispersas, pretende-se contribuir para um aprofundamento metodológico no campo disciplinar em foco.

Antes, contudo, é importante definir melhor o que se entende por literatura. Sem a pretensão de esgotar a questão, tema da teoria literária, explicitase o que se toma aqui por literatura para entender como e por que se a toma como fonte. Seguindo o crítico Antoine Compaignon, vemos que "a tradição teórica considera a literatura como una e própria, presença imediata, valor eterno e universal; [enquanto] a tradição histórica encara a obra como outro, na distância de seu tempo e de seu lugar" (COMPAIGON, 2012). Se é a partir da tradição histórica que a literatura é mobilizada aqui, privilegia-se neste artigo a maneira como a literatura de ficção, romances, contos, poesia e crônicas (gênero híbrido, mas de vasta tradição no Brasil) vêm sendo utilizados como forma de acesso à história das cidades. ${ }^{7}$ Cabe uma última ressalva: ainda que a separação entre ficção e não ficção seja comumente aceita, o crítico inglês Terry Eagleton já mostrou como essa diferença não é tão simples, sendo essas definições algo historicamente construído, o que parece importante de se ter em mente quando se lida com literatura. Defendendo a ideia de "reescritura" das obras a cada nova leitura, Eagleton, no fundo, insiste na instabilidade das classificações. ${ }^{8}$

Duas obras "clássicas": a cidade se revela na literatura

Nem sempre preocupados com a história das cidades stricto sensu, alguns trabalhos forneceram contribuições importantes para seu entendimento, formando uma espécie de "campo ampliado" da história urbana. Como afirma a historiadora Lynn Hunt, "as palavras não reflet[e]m apenas a realidade social e política; [são] instrumentos de transformação da realidade" (HUNT, 200 1, p. 23). Essa via de mão-dupla que se estabelece através dos textos não é evidente nem 
constante, mas, ao notarmos que uma determinada literatura é sensível às transformações da cidade, não podemos esquecer que ela também trata de dar sentido a essa mesma cidade. $\bigcirc$ desafio, expresso de maneira sintética por Adrián Gorelik, é identificar quais são os pontos de intersecção, para perceber onde as distintas lógicas são igualmente potentes, refletindo sobre as relações entre cidade e sociedade, entre cultura material e história da cultura, nos diferentes tempos que as atravessam (GORELIK, 2009).

Pelos exemplos lembrados no início deste texto, é possível perceber que as transformações ocorridas a partir da Revolução Industrial e a crescente urbanização advinda desde então geraram uma literatura mais sensível a essas transformações, não apenas os romances, mas também, como já dito, na poesia e nas crônicas. Vejamos dois trabalhos que lidaram com esse tipo de material e que formularam hipóteses válidas para pensarmos as cidades na história: $\bigcirc$ campo e a cidade na história e na literatura, de Raymond Williams, obra lançada em inglês em 1973,9 e Tudo que é sólido desmancha no ar: a aventura da modernidade, de Marshall Berman, publicado originalmente em 1982. ${ }^{10}$

Ambos são recuperados aqui pela acolhida que tiveram no Brasil, ao menos desde suas traduções na década de 1980." 'Como se sabe, são obras que se detêm na longa passagem do mundo pré-capitalista para a sociedade industrial, e se o objeto de estudo não é a cidade em si - no primeiro caso, a literatura; no segundo, a modernidade -, elas de todo modo têm fornecido inspiração para estudiosos preocupados com a história das cidades. Seja por meio do olhar para os seus procedimentos, mas também pelas suas conclusões, pretende-se recuperar alguns dos argumentos ali expostos que possam explicitar seus caminhos analíticos.

No famoso e muito citado $\bigcirc$ campo e a cidade, ao discutir a poesia e a prosa inglesas a partir desses dois polos espaciais, Raymond Williams elaborou uma compreensão da forma capitalista, se quisermos chamar assim, que enriqueceu o entendimento da metrópole londrina e das metrópoles industriais que surgiram inicialmente na Inglaterra e depois se espalharam pelo mundo, mostrando de maneira sutil e precisa como havia duas realidades sendo transformadas, não apenas vinculadas ao mundo urbano, mas a todo o território. ${ }^{12}$

Partindo dessa premissa, o crítico buscava olhar para o aparecimento das imagens rurais e urbanas na literatura, tentando localizar o momento em que ocorrera uma transformação das mentalidades de modo a se colocar no campo todas as potencialidades de um passado perdido frente à avassaladora transformação das cidades. E o que Williams nota é que essa parecia ser a característica da literatura inglesa desde há muito, podendo-se sempre voltar em busca de um passado idílico cada vez mais recuado no tempo. $\bigcirc$ autor indica como a percepção de um mundo em radical transformação - que se exprime por meio da literatura - não tem lugar apenas com a revolução industrial, sendo os literatos sensíveis a uma transformação de fundo que corroía a ordem rural por dentro, antes mesmo da nova ordem urbana se fazer visível. Sua intenção é identificar a base material dessas mudanças, mostrando ainda que essa leitura não
9. O livro é o resultado da reunião de diversos ensaios do autor, publicados em anos anteriores como artigos e apresentações de coletâneas, e palestras publicadas sob o título The English Novel from Dickens to Lawrence. A primeira edição é de 1973; em português sai em 1989, sendo até hoje reeditado - agora em versão de bolso. Ver Raymond Williams (2011).

10. Escrito entre 1972 e 1981 como tese de doutorado na Universidade de Colúmbia, foi publicado em Nova York em 1982. Em português, saiu a primeira vez em 1986. A "rapidez" da tradução indica como o campo dos "estudos culturais” estava já conformado no Brasil nessa década. Ver Marshall Berman (1986).

11. Os livros foram traduzidos pela Companhia das Letras, editora que, como se sabe, foi responsável no final da década de 1980 e sobretudo nos anos 1990 por contribuir de maneira decisiva para "atualizar" o campo das ciências humanas no Brasil com a tradução de obras ligadas aos chamados "estudos culturais".

12. O autor mostra que tanto a cidade quanto o campo, por estarem organizados pelo mesmo modo de produção, não estavam concretamente separados, mas que historicamente teria havido uma separação ideológica entre os termos, separando-os por meio de imagens opostas. Ver Raymond Williams (2011, p. 12-14 e 80-81). 
13. O autor lembra que Londres experimentara um crescimento de $20 \%$ entre 1821 e 1841, e as cidades industrias do norte cresceriam no mesmo período mais de $40 \%$. Cf. Raymond Williams (2011, p. 248).

14. Stela Bresciani já apontou a "coincidência" do nome da cidade ficcional de Dickens no capítulo sobre a cidade industrial de Lewis Mumford em sua obra $A c i$ dade na história (publicada em 1961), mostrando que para Mumford a mobilização de Dickens tratava-se de um recurso eminentemente retórico. A autora discute a maneira como os estudos urbanos se apropriariam da literatura "para penetrar a esfera da 'realidade urbana'”, chamando a atenção para a falta de mediação entre o texto literário e a história urbana nesses trabalhos. Cf. Maria Stela Bresciani (2015, p. 78-80). é sempre a mesma, podendo ter sentidos às vezes opostos, porque, concordando com Eagleton, os textos sempre são lidos historicamente.

No decorrer das suas análises literárias, Williams evidencia que Londres não deveria ser compreendida como "cidade industrial", no sentido que a expressão veio a adquirir posteriormente, já que mesmo antes - ainda como um centro de manufatura e de distribuição - ela se tornara uma verdadeira metrópole. Posteriormente, essa cidade passaria a abrigar as duas pontas do processo industrial, o menos e o mais especializado, e, a despeito dos avanços tecnológicos, cada vez mais o trabalho pouco especializado ganharia espaço, já que o setor têxtil (segmento particularmente importante para a economia inglesa) migraria para as regiões ricas em carvão no norte do país. Ainda assim, seguindo seu raciocínio, isso não impediu que a ela fossem atribuídos todos os significados de metrópole industrial. Se foram as novas cidades industriais, como Manchester, Birmingham ou Leeds, as verdadeiras protagonistas do crescimento industrial, foi a grandiosidade de Londres "no tempo em que ela era única" que fez despertar a consciência de uma nova dimensão humana, um novo tipo de sociedade que genericamente ligamos ao mundo industrial (WILLIAMS, 201 1, p. 246-259). E essa consciência se expressou e se tornou visível por meio da literatura.

Desse modo, ao recorremos à literatura, abrimos as portas para a compreensão daquela cultura que dá e toma forma num espaço urbano determinado - para além da sua própria materialidade, nas suas representações contemporâneas. As novas cidades industriais, por outro lado, diz ele, "eram outra coisa". Embora ainda emergentes, elas anunciaram de modo decisivo o novo caráter da cidade e as novas relações entre cidade e campo. ${ }^{13}$ Esse caráter seria imortalizado por Dickens na famosa Coketown: ${ }^{14}$

[...] algumas ruas grandes, todas muito parecidas, e ruas muito pequenas, ainda mais parecidas, habitadas por pessoas igualmente parecidas, que chegavam e saíam todas as mesmas horas, fazendo o mesmo som nas mesmas calçadas, para fazer o mesmo trabalho, e para quem todos os dias eram iguais à véspera e ao dia seguinte, e todos os atos eram a imagem do ano anterior e do subsequente (DICKENS, 1854 apud WILLIAMS, 2011 , p. 260).

É dispensável dizer que a história (e a história urbana) desse período é estudada por meio de muitas fontes. Mas o que importa notar é que a síntese expressa por Charles Dickens no parágrafo destacado pelo crítico, pela força da própria imagem, revela de maneira direta e condensada a realidade do mundo industrial inglês, com seu peso esmagador sobre os homens. A imagem literária, nesse caso, parece sintetizar o sentido da experiência dos homens naquele espaço e naquele tempo, ainda que se deva ressaltar que a preocupação de Williams não é com a veracidade das narrativas. Seu intuito, certamente, é mostrar como a Inglaterra foi concebida e retratada naquelas obras ao longo dos séculos, discutindo a ideologia que estaria por trás daqueles "retratos", que levava à permanência de certas imagens atribuídas tanto ao campo quanto à cidade, a despeito da imensa ruptura que os espaços viveram ao longo dos séculos. 
Para Williams, cultura é experiência ordinária, que designa os significados comuns a uma sociedade humana, seus modos de vida usuais, além da sua produção artística e intelectual. E nesse sentido a literatura, entendida como prática cultural, traz elementos fundamentais para a compreensão do mundo social - no nosso caso, para compreender a própria forma urbana. Segundo o crítico, não haveria dúvida de que a arte na sociedade estava sujeita a determinações econômicas - as relações são determinadas pelo estágio de desenvolvimento das forças produtivas - e sociais - os significados e valores de uma classe dominante tendem a ser os formalizados pelas artes. Mas as artes e as práticas culturais, do seu ponto de vista, não apenas refletiriam essa situação determinante, como também produziam significados e valores que, ao entrarem ativamente na vida social, moldariam seus rumos (CEVASCO, 2009). Nesse circuito é que podemos apreender com a literatura a cidade. Sendo a matéria artística historicamente formada, ela estabelece nexos com a vida social, produzindo aquilo que Adorno chamaria de "a historiografia inconsciente de si mesma e de sua época" (ADORNO, 1970, p. 207).

Raymond Williams defende ainda que o artista compartilha com todos nós o que ele chama de imaginação criativa, ou seja, a capacidade de encontrar e organizar novas descrições da experiência e transmiti-las. $\bigcirc$ diferencial do artista é que ele usaria uma habilidade aprendida e especializada. Pensar a criatividade como algo ordinário, como faz o crítico inglês, equivale a ver a arte como uma especificação de um processo geral de descoberta, criação e comunicação, redefinindo seu estatuto e encontrando a maneira de ligá-lo à vida social. Caberia ao críitico perceber o modo pelo qual, de um vasto campo de possibilidades do passado e do presente, certos significados e práticas são enfatizados e outros negligenciados e excluídos. Ainda mais importante, como alguns desses significados e práticas são reinterpretados, diluídos, ou colocados em formas que apoiam ou ao menos não contradizem outros elementos intrínsecos à cultura dominante e efetiva (CEVASCO, 2009).

Sua obra aparece assim como um manancial importante para se pensar as possibilidades de leitura das relações entre a literatura e a cidade - e a sua história. Ao demonstrar por meio da literatura como o processo de metropolização é muito mais complexo do que apenas as transformações advindas da industrialização, por exemplo, Williams oferece um caminho vigoroso para o pensamento sobre o urbano que nos leva a um afastamento das perspectivas dicotômicas entre campo e cidade, mundo industrial e pré-industrial, estruturas arcaicas e estruturas modernas, complexificando o entendimento do mundo social e da própria história das cidades.

Tudo que é sólido desmancha no ar tem sido outra obra inspiradora para aqueles que se dedicam a estudar a história das cidades. Neste livro, Marshall Berman buscou construir uma imagem da modernidade, ou melhor, discutir as imagens múltiplas da modernidade, com o intuito de definir melhor esse conceito. Como a modernidade inevitavelmente se vincula ao território urbano, Berman elege 
15. Berman recupera o socialismo utópico saint-simoniano que buscava dar ao Estado um papel como condutor dos grandes projetos de desenvolvimento nacionais, discutido as distintas possibilidades de desenvolvimento daquele mundo moderno em constituição. espaços determinados (e recortes temporais distintos) para, pela literatura, aproximar-se do seu objetivo. Para ele, a modernidade se revelaria antes de tudo pela ambivalência de significados que consegue incorporar, sendo por isso de difícil apreensão conceitual. Entretanto, seria possível perceber três fases ou tendências que auxiliariam a compreender seus movimentos ao longo da história (BERMAN, 1986, p. 15-34). Ainda que esquemática, essa divisão serve para que Berman selecione seus autores: Goethe, Marx, Baudelaire, Puchkin, Dostoievski, mas também Gogol, Mandelstan, Robert Levine e Alan Ginzberg, entre outros; e suas cidades: Paris, São Petesburgo, Nova York; tendo sempre em mente seu foco central, o estabelecimento da cultura moderna, ou do modernismo.

Em sua compreensão, teria havido um primeiro momento - do início do século XVI até o fim do século XVIII - quando as pessoas começam a experimentar a vida moderna. É justamente a fase em que se estabelece o capitalismo mercantil, quando as economias e as nações europeias se formam como Estados Nacionais e lentamente se desestrutura o mundo feudal. Esse é o período que a leitura do livro de Goethe ajuda a compreender: "O Fausto começa num período cujo pensamento e sensibilidade os leitores do século XX reconhecem imediatamente como modernos, mas cujas condições materiais e sociais são ainda medievais [...]" (BERMAN, 1986, p. 40). Trabalhando com a ideia de oscilações dialéticas entre permanências e rupturas, Berman apreende a passagem da sociedade feudal para o mundo capitalista por meio das situações que Fausto se depara, em seu trato com Mefistófeles. É o que the permite definir esse momento inaugural, e trágico, da modernidade, quando o dinheiro começa a mediar todas as relações sociais. A partir daí, os "'pequenos mundos' serão esvaziados, transformados em conchas vazias, e seus jovens partirão na direção de grandes cidades, fronteiras mais amplas, novas nações, em busca de liberdade de pensar, amar e crescer" (BERMAN, 1986, p. 59). A leitura do clássico livro de Goethe the permite avançar não para uma conclusão simplória, a de que o capitalismo segue em um rumo único e inexorável, mas ao contrário, para pontuar as bifurcações que se colocavam no século XVIII nas disputas entre projetos distintos de desenvolvimento urbano e social. ${ }^{15}$

Em seguida, Berman elege um segundo momento ligado à Revolução Francesa, às suas consequências e reverberações, quando a população (sobretudo francesa, mas com reflexos no restante da Europa) compartilha a experiência revolucionária, tomando consciência de viver em um tempo diferente, material e espiritualmente, mas que, de novo, ainda não rompeu totalmente com o mundo anterior. Para o autor, é esse o momento em que se flagram os desdobramentos da ideia de modernismo e modernização, que se estabelecerão ao longo do século XIX (BERMAN, 1986, p. 85-166). As leituras de Marx e em seguida de Baudelaire esmiúçam contradições do capitalismo ainda em gestação, tomando Paris como espaço privilegiado de observação, situação que Berman confronta em seguida com o que ele chama de "modernismo do subdesenvolvimento", aquele da periferia do capital: a velha Rússia entre o Ocidente e o Oriente (BERMAN, 1986, p. 167). 
Com isso, o autor dá conta de olhar para a consolidação do mundo moderno em espaços distintos, mostrando a plasticidade de um capitalismo que começava a abarcar também as sociedades não ocidentais: "a Rússia do século XIX como um arquétipo do emergente Terceiro Mundo do século XX" (BERMAN, 1986, p. 170). Sua análise do "Projeto Nevski", o imenso bulevar reconstruído no reinado de Alexandre, que teria aberto aos russos, "no coração de um país subdesenvolvido, uma vista de todas as promessas deslumbrantes do mundo moderno" (BERMAN, 1986, p. 187), mostra as leituras que aquela rua em particular encerra, em seus paradoxos e fragmentos, oferecendo aos leitores uma compreensão alargada daquele projeto moderno.

O terceiro momento que Berman define se localiza no século XX, quando o processo de modernização se expandiu a ponto de abarcar o mundo todo, ainda que com especificidades a partir das experiências locais (processo que, se a gente quiser, ainda está em curso). Aqui, Berman se volta para Nova York, sua cidade natal - centro do capitalismo avançado -, e para o projeto de transformação levado adiante por Robert Moses: uma modernização avassaladora e destruidora. Nesse ponto, a literatura de Joyce e a poesia de Alan Ginzberg se mesclam ao discurso de Moses e o de seus inimigos, notadamente a jornalista Jane Jacobs, autora do contundente Morte e vida das grandes cidades, publicado em 1961 (BERMAN, 1986, p. 271-330). Não se conformando com uma leitura fácil e imediata dos textos, Berman mostra que, se o ensaio de Jacobs anunciou "uma grande onda de ativismo comunitário, e uma grande irrupção de ativistas, em todas as dimensões da vida política", o seu discurso de elogio à vida urbana moderna que toma a rua e a família como "microcosmos de toda a plenitude e diversidade do mundo moderno em seu conjunto" foi apropriado pela New Right, buscando a partir daí refletir se haveria naqueles textos "uma espécie de contracorrente de nostalgia por uma família e um bairro nos quais o eu pudesse estar seguramente incrustado, ein'fest Burg, um sólido refúgio contra as perigosas correntes de liberdade e ambiguidade em que todos os homens e mulheres são apanhados" (BERMAN, 1986, p. 306-307). Berman conclui que o mundo urbano de Jacobs, pretensamente misturado e rico, na verdade "é a cidade antes da chegada dos negros":

Seu mundo abrange desde sólidos trabalhadores brancos, na base, a profissionais liberais brancos de classe média, no topo. Não existe nada ou ninguém acima; no entanto, o que é mais importante aqui, não existe nada ou ninguém abaixo - a família de Jacobs não tem enteados. (BERMAN, 1986, p. 308)

E, aqui, a potência do seu trabalho para entender a cidade de Nova York naquela altura, e as cidades norte-americanas em geral. Pois, nos anos 1960, foi para elas que convergiu uma imensa população negra e hispânica que viveria - fulcro da crise das décadas posteriores, quando os empregos desapareceram e fizeram que essa população se transformasse em "párias raciais e econômicos, um enorme lumpenproletariat sem perspectivas ou esperanças" (BERMAN, 1986, p. 
16. Refiro-me à recepção da coletânea organizada por Jacques Le Goff e Pierre Nora, publicada na França em 1974 e traduzida no Brasil em 1976, tomada aqui como obra-síntese dessa renovação historiográfica. Para um panorama sobre o tema, ver Fernando Novais e Rogério Forastieri da Silva (2011, p. 7-70).
308). O autor reflete sobre a escalada da violência nos bairros negros - no seu velho Bronx em especial -, mas introduz um elemento novo na crítica urbana, que não mais apenas as vias expressas de Moses a destruir o bairro, reconhecendo os efeitos das disparidades cada vez maiores entre as classes, polarizações sociais que a tudo e a todos atingiam, impingindo um cenário de crime, violência, ódio e medo ao conjunto da cidade, decorrente da transformação da própria sociedade.

O que se aprende com Berman é que tanto as cidades, quanto a literatura que se produz nelas, não apenas falam da modernidade, mas a qualificam, ao revelar de maneira mais precisa suas ambivalências e sua forma de ser nos países centrais e periféricos, na própria materialização urbana. Nesse sentido, modernidade e experiência urbana formariam um binômio de dupla implicação. A cidade, que se constitui como questão fundamental para os modernos, torna-se uma paisagem inevitável, paradoxalmente polo de atração e de repúdio. E a literatura explorada pelo autor qualifica essa experiência, dando corpo a tal percepção e nos colocando diante dessas ambivalências a partir de cada uma das obras por ele analisadas. Ainda que trabalhando a partir da dicotomia centro/periferia, esse livro, reforçando o argumento da modernidade como um fenômeno multifacetado e que tem nas cidades um espaço privilegiado de análise, ajuda no fundo a questionar as hierarquias entre esses polos e a univocidade dos fenômenos, contribuindo para mostrar os rendimentos do discurso literário para essa compreensão.

Leituras brasileiras: outras aproximações entre cidade e literatura

No Brasil, a renovação historiográfica que levou à ampliação das fontes, abordagens e objetos de pesquisa nos percursos históricos em geral implicou também a expansão do espectro de preocupações sobre as cidades e a sua história. ${ }^{16}$ Isso coincidiu com a implementação dos programas de pós-graduação nas universidades brasileiras, o que contribuiu para a consolidação das pesquisas e para o avanço nas questões metodológicas. Entre os arquitetos e urbanistas dedicados à história urbana, as cidades passavam a ser compreendidas não apenas como artefatos construídos, seu atributo mais intrínseco, mas também como campo de conflitos e de significações. Aos historiadores e cientistas sociais, mais afeitos a lidar com os fenômenos sociais, fazia-se necessário incluir a dimensão material dos espaços, percorrendo esse caminho no sentido inverso. Em ambos os campos, ao se examinar as formas materiais e simbólicas das cidades nas suas figurações literárias, discutia-se e se problematizava a ideia de cidade como locus da modernidade, realçando-se, também aqui, a ambivalência desse conceito.

Trabalhos como Literatura como missão (SEVCENKO, 1983) e Orfeu extático na metrópole (SEVCENKO, 1992), de Nicolau Sevcenko, sobre o Rio de Janeiro e São Paulo; ou os de Flora Süssekind: As Revistas de ano e a invenção do Rio de Janeiro (SÜSSEKIND, 1986) e Cinematógrafo de Letras (SÜSSEKIND, 
1987); ou o de Maria Alice Rezende de Carvalho (inspirada em Richard Morse) sobre o Rio (CARVALHO, 1994) foram frutos dessa concepção do fazer histórico que tomava a cidade como um campo de interesses e um objeto de estudo, não apenas como cenário. Todos eles, de uma forma ou de outra, ainda que com objetivos distintos, ao reconhecerem a literatura como porta de acesso ao fenômeno urbano, ou como já dito, como produto e produtora das cidades, apontaram caminhos para os historiadores urbanos, trabalhando a partir do cruzamento de fontes e jogando luz nova na experiência urbana.

Robert Moses Pechman e Maria Stella Bresciani, a partir da década de 1990, também lançaram considerações sobre o urbano, buscando nos textos ficcionais matéria de reflexão - neste caso, voltados a compreender o fenômeno urbano e a partir dele redefinir a experiência social. ${ }^{17} \mathrm{E}$ igualmente aqui a virada do século XIX para o XX foi tomada como momento privilegiado para essa forma de abordagem, na qual a literatura é fonte para compreender as transformações das capitais brasileiras, que passavam por processos intensos, e quase sempre contraditórios, de modernização, nesse período pós-abolição e republicano. ${ }^{18}$ Arrisco a dizer que foi justamente por meio da literatura de ficção que as contradições se fizeram mais presentes, contrapostas à documentação técnica e oficial que privilegiava o viés modernizador das intervenções. Autores como José de Alencar, Machado de Assis, Lima Barreto, João do Rio, no Rio de Janeiro, ou em São Paulo, Álvares de Azevedo, Mário de Andrade, Oswald de Andrade, Alcântara Machado, entre outros, seriam frequentemente revisitados, contribuindo para explicitar as particulares características da urbanização nos trópicos.

Se essa discussão estava informada pela renovação historiográfica nos países centrais, que aproximava a história dos demais campos do pensamento, da teoria literária e antropologia à linguística e psicanálise, não se pode deixar de ressaltar ainda a fundamental contribuição dada por Antonio Candido para a incorporação da literatura como forma de entendimento social. $\bigcirc$ crítico, sociólogo de formação, que publicara o livro Literatura e sociedade em 1970 reunindo escritos da década anterior, forneceu importantes elementos para a reflexão sobre os sentidos dessa ligação (CANDIDO, 2000). Em seu artigo "A literatura e a vida social" (CANDIDO, 2000, p. 17-40), em especial, Candido elenca formas de entendimento do problema e que podem ser melhor compreendidas a partir da leitura do seu famoso ensaio "A dialética da malandragem" (CANDIDO, 1993, p. 19-55), também publicado em 1970. Por meio da análise literária do livro Memórias de um sargento de milícias, de Manuel Antônio de Almeida, Antonio Candido disseca a formação do Brasil moderno e seus impasses e logra mostrar como aquela obra literária, ao abordar a sociedade carioca pré-abolição sem falar dos escravos nem das classes dirigentes, joga luz em uma parte da sociedade brasileira que permanece entre a "lógica da ordem e da desordem", trazendo elementos para a compreensão da vida social não apenas no Rio, mas nas cidades brasileiras,
17. Ver os estudos de Robert Moses Pechaman (2003), Maria Stela Bresciani (2004). Vale notar que no artigo citado anteriormente, Bresciani propõe um percurso pelos escritos ficcionais da virada do século XIX para o XX, perguntando-se sobre o "ponto de atração incontornável” desses escritos para se pensar as cidades daquele período. Sua abordagem, ainda que não tendo os mesmos objetivos de nosso texto, de certo modo, complementa os temas aqui discutidos, ao buscar definir a importância dos textos ficcionais "para a formação de uma imagem e um saber sobre as cidades, que alimentaram e alimentam o pensamento urbanístico" (BRESCIANI, 2015, p. 59).

18. Ainda que se deva notar que Robert Pechman tem trabalhado também com a literatura urbana contemporânea para pensar o Rio de Janeiro hoje, de Rubem Fonseca a Paulo Lins (2007). 
"sem [entretanto] querer ver a ficção como duplicação da realidade" (CANDIDO, 1993, p. 32). Como afirma em seguida,

Na verdade, o que interessa à análise literária é saber, neste caso, qual a função exercida pela realidade social historicamente localizada para constituir a estrutura da obra -, isto é, um fenômeno que se poderia chamar de formalização ou redução estrutural dos dados externos. (CANDIDO, 1993, p. 32)

Aquele romance, ao ter suprimido o escravo, suprimia o trabalho; ao suprimir as classes dirigentes, tirava de cena os controles do mando. E o que sobrava era esse "setor intermédio e anômico da sociedade", nas palavras de Roberto Schwarz, "cujas características entretanto serão decisivas para a ideologia dela" (SCHWARZ, 1997, p. 132). Em uma sociedade como tal, a conclusão era de que dificilmente a ordem se imporia, pois estava

cercada de todos os lados por uma desordem vivaz, que antepunha vinte mancebias a cada casamento e mil uniões fortuitas a cada mancebia. Sociedade em que uns poucos livres trabalhavam e os outros flauteavam ao Deus dará, colhendo as sobras do parasitismo, dos expedientes, das munificências, da sorte ou do roubo miúdo. [...] Ficou o ar de jogo dessa organização bruxuleante fissurada pela anomia, que se traduz na dança das personagens entre lícito e ilícito, sem que possamos afinal dizer o que é um e o que é outro, porque todos acabavam circulando de um para outro com uma naturalidade que lembra o modo de formação das famílias, dos prestígios, das fortunas, das reputações, no Brasil urbano da primeira metade do século 19. (CANDIDO, 1970 apud SCHWARZ, 1997, p. 132)

A leitura daquela realidade histórica, proposta por Antonio Candido, cujo correlato formal é a dialética da ordem e da desordem, tem enorme rendimento para a compreensão também da história dos espaços urbanos cariocas le brasileiros). Isso por dois motivos: porque sendo as cidades uma realidade com múltiplas dimensões, elas escapam às definições unívocas, não podendo ser compreendidas apenas pela sua dimensão morfológica - a literatura revelando-se aqui outra importante porta de acesso aos espaços e à vida vivida neles. Mas também poderíamos pensar que essa dialética da ordem e da desordem se manifesta na própria materialidade daquela cidade, numa modernização urbanística que jamais se completa, espelhando nesse sentido a própria sociedade na morfologia resultante.

que se defende aqui portanto é que as cidades sejam compreendidas como "um agente coletivo da transformação histórica, um produto material dessa mesma transformação e um ambiente social e intelectual que a perpetua", vistas como "um complexo artefato que reflete fielmente as condições nas quais foi criado, mas que tem a capacidade de impor efeitos - formas de vida e mentalidades muito mais duradouros que essas mesmas condições" (GORELIK, 2009, p. 39). Por isso, essas três dimensões, a do artefato construído, a das relações sociais e a das representações, devem ser encaradas na história urbana como uma espécie de sistema solidário, e não como causa e consequência, ou apenas como reflexo 
uma da outra. E é aqui, insisto, que a literatura aparece como fonte privilegiada: ao promover a formalização ou redução estrutural dos dados externos, como ensinou Candido, ela abre ao pesquisador a possibilidade de, por meio dessa fonte particular, qualificar a vida nas cidades.

Das intuições à realização: três tentativas de lidar com a questão

Essas questões vêm acompanhando minhas reflexões sobre a história das cidades há um bom tempo. Retomo aqui uma primeira incursão pelo tema, a dissertação de mestrado na qual buscava compreender as imagens da São Paulo moderna na década de 1920 - quase um topos da "identidade" paulista ligada àquela década - por meio de crônicas publicadas nos jornais. ${ }^{19}$ Os textos de Menotti del Picchia escritos em e sobre São Paulo durante toda a década permitiram enfrentar o desafio de incorporar a literatura (nesse caso, as crônicas daquele poeta modernista) como fonte para a construção da narrativa histórica urbana. Ao tomar aquele material como um documento privilegiado das imagens da cidade nos anos 1920, fui tragada pelas ambivalências da São Paulo moderna, matizando conceitos e representações que pareciam cristalizados. Foi a existência desse corpus documental consistente crônicas diárias sobre a cidade publicadas no jornal Correio Paulistano entre 1919 e 1930 e assinadas por Helios (pseudônimo de Menotti del Picchia) - o que me levou a esboçar uma metodologia de trabalho para compreender o urbano que incorporava a dimensão simbólica, dando a ela um status tão importante quanto a dimensão material da cidade. Essa operação pareceu ser fundamental para entender a modernidade e a modernização da cidade, seus meios e expressões, pois ao serem colocadas em perspectiva, as duas dimensões evidenciavam descompassos e complementaridades entre a materialidade e as suas representações, trazendo à tona a dimensão dos conflitos e enriquecendo a compreensão do urbano por afastar as explicações duais e excludentes que antepunham atraso e modernidade. ${ }^{20}$

Num momento em que São Paulo começava a vivenciar o surgimento de extratos médios que consumiam e que a produziam, fosse como discurso, fosse como prática, era impossível não seguir a coluna de modas ou não dar atenção aos anúncios e à seção de fatos diversos publicados na mesma página das crônicas publicadas na coluna Crônica Social. Isso me fez perceber como os temas da cidade estavam vinculados à formação de uma cultura urbana, explicitada naquele material tanto quanto nas crônicas que relatavam mais diretamente a "modernidade" paulista da Semana de 22 e os embates entre os modernistas à transformação do espaço urbano com suas obras de embelezamento e remodelação. Ao mesmo tempo, o elevado número de crônicas sobre os caipiras na cidade, ainda que retratados de maneira cômica e caricata, parecia revelar uma realidade provinciana ainda muito presente, revelando-se parte dessa mesma modernização e não resquício de outros tempos - impondo a polissemia da modernidade paulistana. Um exemplo talvez ajude a explicitar o ponto.
19. A dissertação foi defendida em 2005 com apoio da Fapesp e publicada pela Alameda Editorial, com auxílio da mesma fundação, em 2008.

20. Apoiando-me também, por certo, em autores referidos na primeira parte deste artigo, que lia sem grandes preocupações teórico-metodológicas, como uma espécie de inspiração, e naqueles que haviam escrito sobre cidade naquela década, notadamente Nicolau Sevcenko (1992), cujo subtítulo de sua obra, "os frementes anos vinte", já indica um caminho de compreensão da modernidade paulista que o trabalho acabou por discutir. 
Na crônica "A odisseia do Belarmino", publicada em 2 de outubro de 1920, Menotti evidencia como a capital paulista atraía os caipiras do interior pelas oportunidades infinitas que parecia oferecer. Mas, ao procurar moradia, Belarmino, um infeliz coronel - personagem típico dessas crônicas, o caipira do interior que não se adapta na cidade grande - que só queria se mudar com sua cara-metade para a capital para poder acompanhar de perto as comemorações do Centenário da independência, que já começavam a ser preparadas - depara-se com uma situação que dava mostras de que o crescimento intenso e desordenado imposto à cidade não ocorria sem consequências. Indo de um bairro a outro, Belarmino parece jamais achar algo decente:

[...] procura daqui, procura dali, vai pro Brás, vai pra Lapa, mexe pra cima, mexe pra baixo, e... [...] um horror! Um absurdo! , [...] Pois mal os jornais saem, compro logo para ver o 'aluga-se': Aluga-se na rua carioca uma ótima casa. Vasta, nova, para família de tratamento. [Mas ele continua:] $\bigcirc$ preço já é o do sem-vergonha: quinhentos mil reis uma pocilga, seiscentos um cochicholo, setecentos um curral; oitocentos uma cuia... Imagine se meus colonos tivessem que pagar aluguel na fazenda! Eu hoje era um conde Matarazzo! (HELIOS, 1920)

Helios, o cronista, pergunta então se era isso a causa de tanto abatimento: Pudera! Atrás dessas arapucas andei dois meses, gastei 5 pares de botas e dois contos de automóvel e bonde. Agora resolvi mandar buscar o Piquira que eu deixei em Piquiri, no pasto do Saturnino Goiaba. Vou começar a romaria a cavalo... / E a sua mulher?! / Quis se suicidar com uma lata de creolina... Quanto a mim, ou vou parar no Juqueri ou viro bolchevista! (HELIOS, 1920)

Não se sabe se a mulher do Belarmino vai se suicidar porque não acham casa ou de vergonha do marido começar a ronda a cavalo em plena capital às vésperas do centenário, quando se preparava a maior exibição pública de progresso e civilidade. O fato é que a crônica nos coloca diante das dificuldades do caipira na cidade moderna e de todas as implicações dessa tal modernidade, seus descompassos e entraves, abrindo caminho para a compreensão mais efetiva do desenvolvimento urbano complexo que se esboçava no início do século XX. As imagens da cidade moderna eivadas dessas situações provincianas - ainda que tratadas de maneira cômica, insisto - matizavam a ideia de total cosmopolitismo identificada à década de 1920 paulista: a São Paulo dos imigrantes, a locomotiva do Brasil, o espaço do Brasil moderno por excelência, onde mais nada remeteria a um passado de origem colonial ou a um mundo não urbano.

Ora, se a literatura fornecia pistas para uma compreensão mais complexificada do "urbano", no doutorado busquei estudar a obra de Richard Morse sobre a história de São Paulo - De comunidade à metrópole: a biografia de São Paulo, lançada em 1954 e republicada em 1970 como Formação histórica de São Paulo: de comunidade à metrópole - justamente pelo fato de essa clássica "história urbana" tomar dois movimentos literários 
como balizas temporais e, mais que isso, valer-se de autores e textos literários como fontes para a história da cidade. ${ }^{21}$

Ao explicitar os pressupostos dessa história cultural urbana avant la lettre, busquei avançar na compreensão metodológica desse procedimento, por meio da análise de uma obra concreta, escrita por um historiador que lançava mão da literatura em seu estudo, muito antes de qualquer sistematização disciplinar desse "novo" campo, não como referência retórica, mas como estruturadora mesma do próprio texto. Nesse sentido, a tese tenta explorar diversos caminhos, partindo das reflexões do próprio autor, já que suas opções metodológicas não haviam sido construídas de maneira ingênua ou casual. Leitor de Lewis Mumford, ${ }^{22}$ Morse afirmava que o foco do estudo de uma cidade devia ser "o modo de vida da população" ou "a maneira como homem e meio interagem". ${ }^{23}$ Sem fixá-la numa descrição rígida, como faziam os sociólogos pois que se corria o risco de reduzi-la -, o historiador apontava para a compreensão da cidade dentro de um processo de duração longa, definindo-a pela vida urbana que ali se estabelecera. Mas, é o que defendo na tese, foi ao encontrar em São Paulo Antonio Candido no momento em que o jovem crítico e professor da Sociologia formulava suas interpretações sobre a formação da literatura brasileira que esses pressupostos ganharam forma e conteúdo. No contato com o crítico brasileiro, Richard Morse construiu o arco histórico da evolução urbana de São Paulo entre o Romantismo e o Modernismo, apoiando-se para tanto nas figuras de Álvares de Azevedo e Mário de Andrade, em seus escritos ficcionais e memorialísticos sobre a cidade e nas próprias experiências desses autores em São Paulo. A partir daí, o historiador monta sua tese sobre a formação urbana de São Paulo, que teria uma imensa longevidade. ${ }^{24}$

artefato urbano foi alvo da análise de Morse, mas só se tornava inteligível quando visto também como campo de tensões, e, mais que isso, era por meio das suas representações (de onde a cultura ganhava centralidade na análise) que se podia chegar de forma mais completa a esse entendimento. Como na cidade de São Paulo teria sido a partir do século XIX, parafraseando Morse, que as opiniões se fragmentaram, que o conceito de progresso fora assimilado, que a chegada de estrangeiros implicara na incorporação de novos valores e que o espírito do novo tempo e o próprio desenvolvimento material haviam levado seus habitantes a tomarem "uma nova consciência de si mesmos", apenas o "talento" (a palavra é dele) do historiador é que poderia ser capaz de juntar estudos científicos e descrições de época, para dar um sentido geral que se traduzisse numa narrativa histórica (MORSE, 1949, p. 42). A literatura, portanto, não era a única entrada para o passado, mas estruturava o próprio olhar para a história urbana, dando a Morse os elementos para a compreensão do ethos paulista, o que, para ele, explicava os caminhos que a cidade havia tomado. Por isso, o autor recua ao início do século XIX, e não ao seu final, ponto recorrentemente tomado pela bibliografia como de inflexão, para indicar um suposto corte. Para Morse, foram as transformações no ethos paulista, a partir da
21. A tese foi defendida em 2013 e contou com apoio da Fapesp.

22. Autor que mereceria também um aprofundamento quanto a sua contribuição para a formulação de uma perspectiva "cultural" no estudo da história das cidades, mas que foge ao escopo deste trabalho. Fiz uma breve incursão ao tema na tese de doutorado (CASTRO, 2013a, capítulo 2). Ver ainda Maria Stela Bresciani (2015).

23. Trata-se do artigo "O pesquisador social e o historiador moderno", publicado antes de o autor terminar sua tese, na qual Morse estabelece seus pressupostos mais teóricos e de procedimentos, digamos assim (MORSE, 1949).

24. Sobre a fortuna crítica da obra ver CASTRO, 2013b. 
25. Trata-se do projeto "As cidades e as ideias: a América Latina como problema para a história da cidade e do urbanismo entre práticas e discursos (1930-1960).

26. Foi a partir desse ponto que reformulei o projeto de pesquisa focalizando em três cidades e alterando o recorte temporal para a segunda metade do século XX - "As cidades e as ideias. A América Latina como problema para a história da cidade e do urbanismo entre práticas e discursos: Lima, Bogotá, São Paulo (1940-1970)" -, buscando estabelecer um corpus documental mais preciso.
Independência, que permitiram e ampararam as transformações materiais advindas do trinômio café-ferrovia-imigração, dando à capital as condições de se tornar uma metrópole no século seguinte.

Como se percebe por essas breves considerações, o assunto está longe de ter alcançado qualquer acomodação. $\bigcirc$ que é necessário refletir com mais acuidade é como incorporar a literatura nas análises urbanas de modo a trazer novos elementos de compreensão das cidades, e não apenas dizer pela literatura o que se sabe por outras fontes, tomando-a como mera ilustração. Morse, me parece, alcançou isso ao manejar a literatura de Álvares de Azevedo e Mário de Andrade no cruzamento com outros materiais, diferindo das leituras que se apoiavam em uma compreensão mais economicista do fenômeno urbano e que não tinham dúvidas em enfatizar o trinômio citado acima como causa do desenvolvimento urbano. $\bigcirc$ que o autor faz é deslocar a pergunta e questionar como a cidade pode sustentar aquele caminho, apoiada em quais estruturas mentais e sociais. Lembrando aqui as considerações do historiador francês Bernard Lepetit, de "que o conhecimento histórico progride não tanto por resolver os problemas quanto por modificar a forma de colocá-los" (LEPETIT, 1996, p. 78), pode-se dizer que Morse, por se perguntar não pelo que teria transformado materialmente a cidade, mas sobre o que teria levado seus habitantes a buscarem essa transformação, consegue propor um olhar qualificado e potente para a cidade e a sua história urbana.

Tendo iniciado mais recentemente um projeto de pesquisa cuja intenção é aprofundar essa reflexão, ampliei o território de preocupações de São Paulo para as cidades latino-americanas. ${ }^{25}$ Ao tomar de empréstimo o título do famoso livro de José Luís Romero - As cidades e as ideias (ROMERO, 2002) -, a pesquisa quer olhar para as cidades latino-americanas a partir da discussão de uma possível identidade que teria se forjado na urbanização do continente, tendo no segundo pós-Guerra um momento privilegiado para análise (GORELIK, 2005). A partir dos escritos de Ángel Rama, reconhece-se uma espécie de boom literário nos anos 1940 e 1950, cujo mote é a urbanização, seus conflitos e consequências (RAMA, 2001, p. 150). Essa literatura, encravada no conflito urbano, teria emergido como fruto do trabalho de uma geração de escritores que se firmou no subcontinente rompendo com identidades nacionais. E é ela que será tomada como uma fonte privilegiada para se discutir a própria ideia de uma "cidade latino-americana" (GORELIK, 2005).

Com o olhar voltado inicialmente para três cidades do subcontinente, Lima, Bogotá e São Paulo, venho me aproximando da realidade latino-americana para identificar constantes mas também peculiaridades que tragam rendimentos a fim de discutir a constituição dessa possível identidade. Em uma primeira incursão ao tema, explorei as relações entre a literatura de Júlio Ramon Ribeyro e a cidade de Lima, capital do Peru, discutindo a ideia de marginalidade urbana como uma das imagens-síntese da cidade latino-americana constituída na segunda metade do século XX (CASTRO; ARAVECCHIA-BOTAS, 20 14). ${ }^{26}$ Lima é tomada como um caso 
importante da urbanização do continente, por ter vivido um processo de favelização intenso e precoce, de onde uma série de preceitos e reflexões de maior alcance deriva. Desde a década de 1940 as barriadas limeñas ocupariam os arredores da cidade e, com isso, o Estado peruano levou adiante uma série de ações de modo a mitigar os efeitos dessa ocupação, trabalhando a partir dos preceitos urbanísticos modernos, projetando uma série de unidades vecinales para os trabalhadores urbanos. $\bigcirc$ discurso técnico, apoiado nos ideais desenvolvimentistas dos intelectuais ligados à Comissão Econômica para a América Latina e o Caribe (Cepal), indicava um caminho de desenvolvimento industrial traçado desde o período de substituição das importações propiciadas pelo conflito mundial, apoiando uma urbanização constante e consistente. A se crer nesse esquema, os países "subdesenvolvidos" venceriam etapas até chegar aos índices de desenvolvimento e modernização vividos pelos países centrais.

Contudo, essa perspectiva será questionada em fins dos anos 1960 e sobretudo na década de 1970, quando a chamada Teoria da Dependência se torna hegemônica no pensamento social da região. A literatura do escritor peruano Júlio Ramón Ribeyro permite perceber uma deriva anterior no esquema, e a leitura do conto "Ao pé da escarpa", escrito em 1959 e publicado em 1964, permite afirmar isso. A história se refere às observações da vida limenha na década de 1950 - o autor passaria a viver em Paris como embaixador da Unesco desde 1961 - por meio da história de uma família pobre, um pai e dois filhos que vivem em uma praia deserta perto da cidade. ${ }^{27}$

$\bigcirc$ conto abre com a imagem de uma figueira-brava, "essa planta selvagem que brota e se multiplica nos lugares mais amargos e escarpados" (RIBEYRO, 2007, p. 95), o que nos indica de algum modo de que matéria também é feita aquela gente. Tentando sobreviver, constroem uma primeira tapera num barranco deserto entre a escarpa e o mar. Paulatinamente surgem novos personagens naquele mundo vazio: primeiro um homem de rua, que se aproxima do pai e presta serviços em troca de comida e abrigo. Depois, veranistas de domingo que começam a frequentar a praia quase selvagem, exigindo sua limpeza e alguma comodidade. Pai, filhos e homem se entregam com afinco à tarefa de limpar a areia e retirar do mar vergalhões de ferro que impedem o banho, em troca de alguns trocados. Nessa tarefa, um filho morre afogado. Subitamente, surgem outros pobres, desta vez em maior quantidade, ocupando com barracos construídos do dia para a noite o terreno logo acima da escarpa. Homens do governo - não se sabe ao certo - chegam para inspecionar a área, fazendo medições e mostrando interesse pelos terrenos. $\bigcirc$ filho sobrevivente se casa e vai embora. A polícia prende o homem de rua. Querem expulsar os moradores, mas o velho resiste, o terreno the pertence por direito:

- Estão jogando a favela no mar.

Eles se contentavam em responder:

- É um abuso.

Nós sabíamos, é claro, mas o que fazer? Estávamos divididos, brigados, não tínhamos plano, cada qual queria fazer do seu jeito. Uns queriam ir embora, outros, protestar. Alguns, os
27. É justamente nesse período que Lima e Callao (seu porto) se tornarão uma entidade única. Até então, a cidade está separada do porto e não há quase nenhum desenvolvimento "balneário" nas praias do seu litoral. 
28. A ideia de marginalidade social torna-se a partir da década de 1970 uma figura comum na leitura da urbanização do subcontinente. E foi justamente outro peruano, Aníbal Quijano, quem buscou dar maior precisão conceitual ao tema (ARAVECCHIA-BOTAS; CASTRO, 2016). mais miseráveis, os que não tinham trabalho, se alistaram na companhia e destruíram suas próprias casas.

Mas a maioria foi descendo pela ribanceira. Erguiam suas casas a vinte metros dos tratores para, no dia seguinte, recolher o que sobrava delas e voltar a erguê-las dez metros adiante. (RIBEYRO, 2007, p. 123)

As casas, construídas com os refugos da expansão urbana da própria cidade, são todas demolidas. Chamando de volta o filho e a nora grávida, os três partem juntos para uma nova franja da cidade, um pouco mais distante e ainda desocupada, onde começarão tudo de novo. Ao encontrarem uma figueira-brava, "cavando entre as pedras, fincamos a primeira viga da nossa casa nova" (RIBEYRO, 2007, p. 128). No meio do século XX, em plena marcha de modernização e progresso, ao colocar o foco naqueles que estão sendo expulsos do processo, a literatura de Ramón Ribeyro joga luz na face ainda oculta do processo de modernização daquelas cidades. Pode-se aferir pelo conto como a ideia de marginalidade social - ainda não nomeada - começa a fazer parte da realidade, sendo mote para a própria criação literária, que dela tira sua força. A ida para uma nova margem não habitada daquela cidade materializa o processo da marginalização da população, "que brota e se multiplica nos lugares mais amargos e escarpados" das cidades. ${ }^{28}$ Se hoje compreendemos esse fenômeno com mais clareza, ao cruzar discursos contemporâneos, literário e técnico, podemos discutir de modo mais qualificado as opções tomadas àquela altura pelo Estado e pela sociedade, e a própria construção da cidade.

Ora, se a proposta subjacente à história cultural é "decifrar a realidade do passado por meio das suas representações, tentando chegar àquelas formas, discursivas e imagéticas, pelas quais os homens expressam a si próprios e o mundo" (PESAVENTO, 2005, p. 42), e se a literatura de ficção pode ser compreendida como "um documento que abre portas para a sua cultura" (GAY, 2010, p. 15), como defenderam autores que se dedicaram a pensar o problema ao longo de seus trabalhos, parece evidente a potência desse tipo de fonte para se escrever uma história cultural urbana das cidades latino-americanas.

Os limites dessa abordagem, entretanto, certamente aparecerão com o desenvolver da pesquisa. Partindo de uma concepção sistêmica das cidades, como sintetizou Bernard Lepetit, buscamos nesta nova pesquisa entendê-las como um elemento do sistema que as englobam, mas também capazes de formar sistemas cujos elementos adquirem sentidos uns em relação aos outros (LEPETIT, 1996). Ao enfrentar o desafio de buscar evidenciar a via de mão-dupla entre cidade e literatura, mostrando que, se a cidade produz discursos, esses discursos também produzem cidades - sejam mentais, sejam concretas -, certamente outras fontes devem ser mobilizadas. Nesta nova investigação, pretende-se recuperar também o discurso especializado dos arquitetos e urbanistas unidos em torno de organismos internacionais e que publicavam seus textos em revistas que circulavam por todo o continente. Mas, 
como dito, é no cruzamento dos dois olhares, discursos especializados e não especializados, veiculados em materiais literários, iconográficos e documentais (no sentido estrito), que se pretende propor uma análise histórica de maior alcance. ${ }^{29} \bigcirc$ que se fez aqui, por ora, foi lançar algumas questões para o debate.

\section{REFERÊNCIAS}

ADORNO, Theodor. Teoria estética. São Paulo: Martins Fontes, 1970.

ALMANDOZ, Almandoz. Notas sobre historia cultural urbana: una perspectiva latinoamericana. Perspectivas urbanas/Urban Perspectivas, Barcelona, ETSAV, v. 1, n.1, p. 29-39, 2002.

ANHEIN, Étienne; LILTI, Antoine. Savoirs de la littérature: introduction. Annales: Histoire, Sciences Sociales, Paris, Editions de l'E.H.E.S.S., 65eme année, v. 2, p. 253260, 2010.

ARAVECCHIA-BOTAS, Nilce; CASTRO, Ana Claudia Veiga de. Urbanização, marginalidade e dependência: Manuel Castells e Aníbal Quijano entre Europa e América Latina (1950-1970). Texto apresentado no VIII Congresso Conselho Europeu de Pesquisas Sociais na América Latina (Ceisal), Instituto de Ibero-América, Universidade de Salamanca, 2016, s/p.

ARRUDA, Maria Arminda do Nascimento. Metrópole e cultura: São Paulo no meio século XX. Bauru: Edusc, 2001.

AUERBACH, Eric. La cour et la ville. In: Ensaios de literatura ocidental. Tradução de Samuel Titan Jr. e Manuel Marcos Macedo. São Paulo: Duas Cidades; Editora 34, 2007. p. 211-278.

BERMAN, Marshall. Tudo que é sólido desmancha no ar: a aventura da modernidade. Tradução de Carlos Felipe Moisés e Ana Maria Imoriatti. São Paulo: Companhia das Letras, 1986.

BRADBURY, Malcon. As cidades do modernismo. In: ; MCFARLANE, James (Orgs.). Modernismo: guia geral (1890-1930). Tradução de Denise Bottmann. São Paulo: Companhia das Letras, 1989. p. 73-82.

BRESCIANI, Maria Stela. O literato, o cronista e o urbanista. Imagens de São Paulo nos anos 1910-1920. In: PESAVENTO, Sandra Jatahy. (Org.). Escrita, linguagem, objetos: leituras de História Cultural. Bauru: Edusc, 2004. p. 115-146.

Literatura e cidade. In: CARDOSO, Selma et al. (Orgs.). Arte e cidades: imagens discursos e representações. Salvador: Ed. UFBA, 2015. p. 57-88.

CANDIDO, Antonio. A literatura e a vida social. In: Literatura e sociedade [1970]. São
29. A pesquisa se apoiará no cruzamento de dois sistemas de fontes principais: a literatura - por meio da definição de determinados autores para cada uma das cidades em foco (como o caso de Júlio Ramón Ribeyro, aqui mencionado, em Lima); e o discurso especializado dos arquitetos e urbanistas sobre os temas urbanos - veiculados em publicações especializadas. Inicialmente limitei a investigação a três publicações, a saber: a revista $E$ Arquitecto Peruano (publicada em Lima); a revista Proa (publicada em Bogotá) e a revista Habitat (publicada em São Paulo), para selecionar temáticas e profissionais em cada uma das cidades.

Paulo: T. A. Queiróz, 2000. p. 17-40. 
A dialética da malandragem. Revista do Instituto de Estudos Brasileiros, USP, n. 8, p.67-89, 1970. Republicado em: O discurso e a cidade. São Paulo: Duas Cidades, 1993. p. 19-55.

CARVAlHO, Maria Alice Rezende de. A produção de uma cidade: o Rio de Janeiro por seus autores. In: Quatro vezes cidade. Rio de Janeiro: SetteLetras, 1994. p.15-63.

CASTRO, Ana Claudia Veiga de. Moderna, nacional, estrangeira. A imagem de São Paulo nos anos 1920 nas crônicas de Menotti del Picchia. 2005. 178 p. Dissertação (Mestrado) - Faculdade de Arquitetura e Urbanismo, Universidade de São Paulo, São Paulo, 2005.

A São Paulo de Menotti del Picchia: arquitetura, arte e cidade nas crônicas de um modernista. São Paulo: Alameda Editorial; Fapesp, 2008.

Um americano na metrópole [latino-americana]: Richard Morse e a história cultural urbana de São Paulo (1947-1970). 2013. 364 p. Tese (Doutorado) - Faculdade de Arquitetura e Urbanismo, Universidade de São Paulo. São Paulo, 2013a. Disponível em: <http://www.teses. usp.br/teses/disponiveis/16/16133/tde-06082013-142628/pt-br.php>.

Leituras e leitores de Richard Morse: a trajetória de um livro sobre a formação da metrópole paulista. Anais do Museu Paulista: História e Cultura Material, v. 21, n. 2, p. 179193, jul./dez. 2013b.

; ARAVECCHIA-BOTAS, Nilce. Visões e representações da marginalidade no território: de Lima à metrópole latino-americana. In: URQUIDI, Vivian et al. (Orgs.). Anais do Seminário Identidades e Representações na América Latina. São Paulo, Prolan-USP, p. 73-87, 2014.

CHARLE, Christophe. A gênese da sociedade do espetáculo: teatro em Paris, Berlim, Londres e Viena. Tradução de Hildegard Feist. São Paulo: Companhia das Letras, 2012.

CHARTIER, Roger. Leituras e leitores na França do Antigo Regime. Tradução de Alvaro Lorencini. São Paulo: Edunesp, 2012.

CEVASCO, Maria Elisa. Para ler Raymond Williams. Rio de Janeiro: Paz e Terra, 2009.

COMPAIGNON, Antoine. Literatura para quê?. Tradução de Laura Brandini. Belo Horizonte: Ed. UFMG, 2012.

EAGLETON, Terry. Teoria da literatura: uma introdução. Tradução de Waltensir Dutra. São Paulo: Martins Fontes, 2006.

GAY, Peter. Represálias selvagens: realidade e ficção na literatura de Charles Dickens, Gustave Flaubert e Thomas Mann. Tradução de Rosaura Eichenberg. São Paulo: Companhia das Letras, 2010.

GORELIK, Adrian. A produção da "cidade latino-americana". Tempo Social. Revista de Sociologia da USP, São Paulo, v. 17, n. 1, p. 111-133, 2005.

Cultura urbana sob novas perspectivas. Entrevista de Ana Castro e Joana Mello. Novos

Estudos, Cebrap, São Paulo, n. 84, p. 235-249, 2009. 
HELIOS [Pseudônimo de Menotti del Picchia]. A odisseia do Belarmino. Correio Paulistano, São Paulo, p. 4, 2 out. 1920.

HUNT, Lynn. História, cultura e texto. In: (Org.). A nova história cultural. Tradução de Jefferson Luís Camargo. São Paulo: Martins Fontes, 2001. p. 1-29.

LE GOFF, Jacques; NORA, Pierre. Faire de l'Histoire, Nouveaux problèmes, nouvelles approches, nouveaux objets. Paris: Gallimard, 1974. 3 v.

LEPENIES, Wolf. As três culturas. Tradução de Maria Clara Cescato. São Paulo: Edusp, 1996.

LEPETIT, Bernard. Por uma nova História Urbana. Seleção e apresentação de Heliana Angotti Salgueiro; tradução de Cely Arena. São Paulo: Edusp, 1996.

MAGRIS, Claudio, O romance é concebível sem o mundo moderno?. In: MORETTI, Franco (Org.). A cultura do romance. Tradução de Denise Bottman. São Paulo: Cosac Naify, 2009. p. 999-1028.

MORETTI, Franco (Org.). A cultura do romance. Tradução de Denise Bottman. São Paulo: Cosac Naify, 2009.

MORSE, Richard. O pesquisador social e o historiador moderno. Revista do Arquivo Municipal, São Paulo, n. 113, p.36-52, 1949.

NOVAIS, Fernando; SILVA, Rogério. Introdução. In: (Orgs.). Nova História em perspectiva. Diversos tradutores. São Paulo: Cosac Naify, 2011. p. 7-70.

PECHMAN, Robert Moses. O mel e o fel da cidade: lendo folhetins e romances em busca de alguma moral urbana. Espaço \& Debates, São Paulo, v. 23, n. 43-44, p. 71-77, jan.-dez. 2003.

Desconstruindo a cidade: cenários para a nova literatura urbana. Revista Rio de Janeiro, n. 20-21, p. 31-40, jan.-dez. 2007.

PESAVENTO, Sandra Jatahy. História E bistória cultural. Belo Horizonte: Autêntica, 2005.

PONTES, Heloísa. Intérpretes da metrópole: história social e relações de gênero no teatro e no campo intelectual, 1940-1968. São Paulo: Edusp, 2011.

RAMA, Ángel. Meio século de narrativa latino-americana (1922-1972). In: AGUIAR, Flavio; GUARDINI, Sandra (Orgs.). Angel Rama: literatura e cultura na América Latina. Tradução de Raquel dos Santos e Elza Gasparotto. São Paulo: Edusp, 2001. p. 111-208.

RAMINELLI, Ronald. História urbana. In: CARDOSO, Ciro Flamarion; VAINFAS, Ronaldo (Orgs.). Domínios da História: ensaios de teoria e método. Rio de Janeiro: Elsevier, 1997. p.185-202.

RIBEYRO, Júlio Ramón. Ao pé da escarpa [1959]. In: Só para fumantes. Tradução de Laura Janina Hossiasson. São Paulo: Cosac Naify, 2007. p. 95-128.

ROMERO, José Luis. As cidades e as ideias [1973]. Tradução de Bella Josef. Rio de Janeiro: Ed. UFMG, 2002.

Annals of Museu Paulista. v. 24. n.3. Sept.-Dec. 2016. 
SEVCENKO, Nicolau. Literatura como missão. São Paulo: Brasiliense, 1983.

Orfeu extático na metrópole, São Paulo: Companhia das Letras, 1992.

SCHWARZ, Roberto. Pressupostos, salvo engano, da dialética da malandragem. In: Que horas são? São Paulo: Companhia das Letras, 1997. p. 129-156.

STIEBER, Nancy. Microhistory of the Modern City: Urban Space, its Use and Representation. Journal of the Society of Architectural Historians, v. 58, n. 3, Special Issue, Chicago: Society of Architectural Historians, p. 382-391, Sept. 1999.

SÜSSEKIND, Flora. As Revistas de Ano e a invenção do Rio de Janeiro. Rio de Janeiro: Nova Fronteira, 1986.

Cinematógrafo de Letras: literatura, técnica e modernização do Brasil. São Paulo: Companhia das Letras, 1987.

WILLIAMS, Raymond. O campo e a cidade na bistória e na literatura [1973]. Tradução de Paulo Henriques Britto. São Paulo: Companhia das Letras, 2011.

Artigo apresentado em 28/03/2016. Aprovado em 28/12/2016. 